\title{
Intestinal lymphangiectasia presenting with duodeno-jejunal polyposis: enteroscopic findings
}

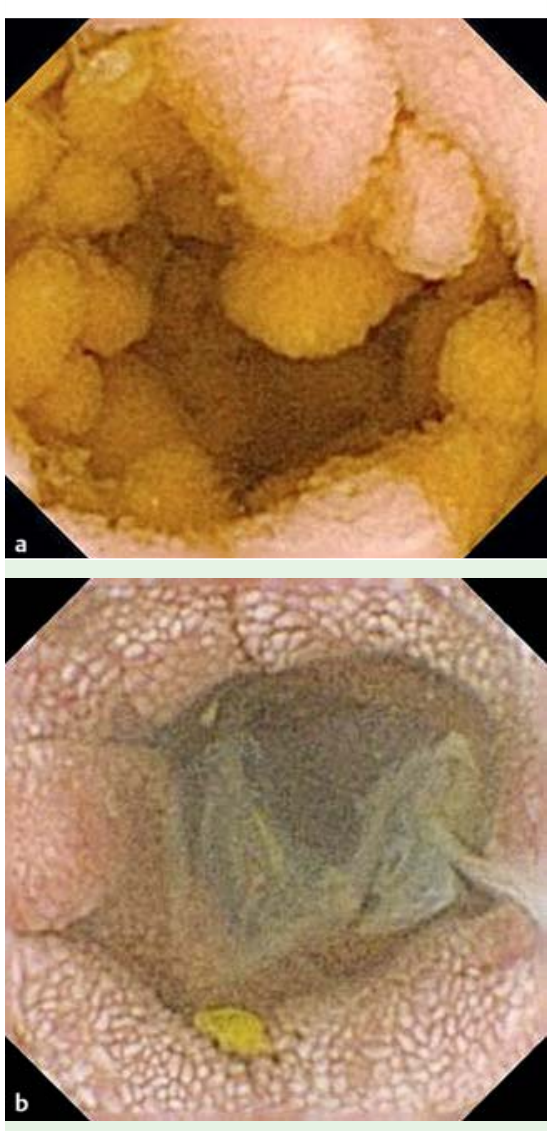

Fig. 1 Capsule endoscopic findings. a Numerous filiform-like polyps seen in the jejunum. b Chylous exudates covering the jejunal mucosa.

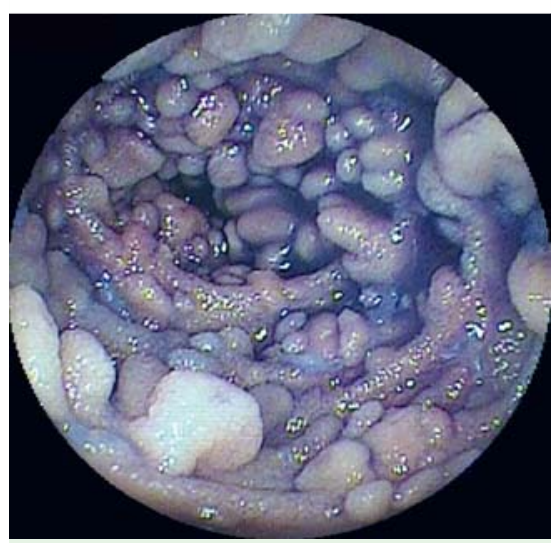

Fig. 2 Double-balloon endoscopy (DBE) findings: numerous filiform-like polyps along with diminutive whitish spots.

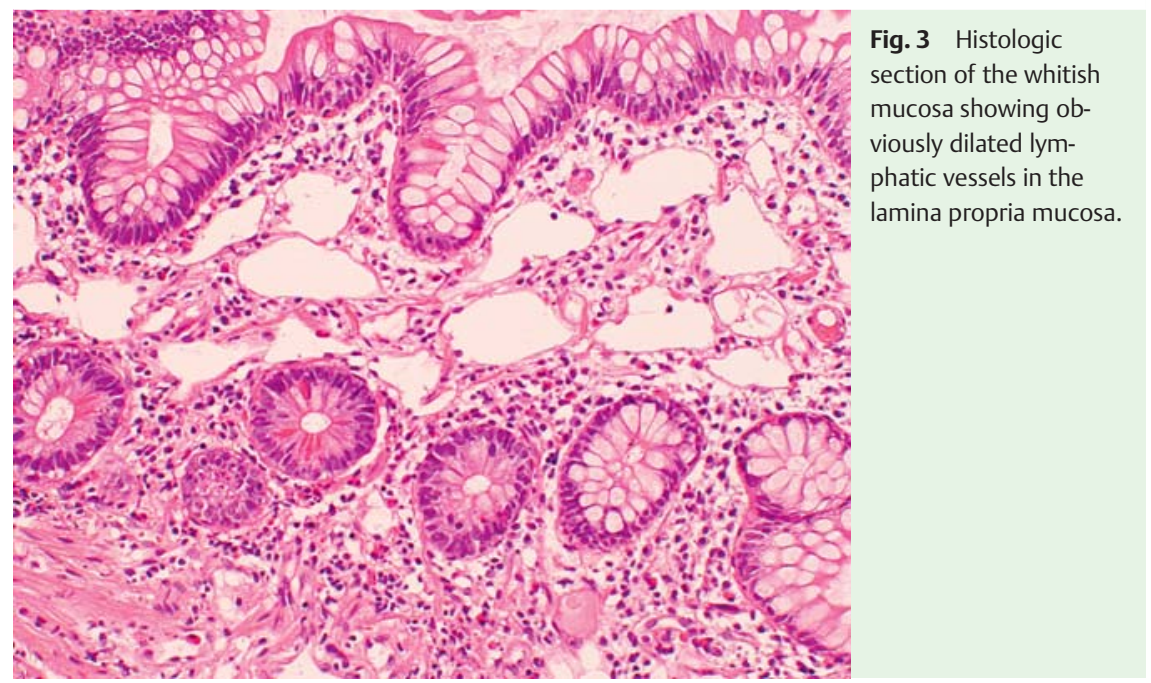

A 55-year-old woman with a pelvic fracture was referred by the orthopedic department at our hospital for severe hypoproteinemia. The patient had been diagnosed as having primary intestinal lymphangiectasia at the age of 25 . Under capsule endoscopy, numerous filiformlike polyps with whitish villi were observed from the distal duodenum to the jejunum ( $\bullet$ Fig. 1 a) with exudation of a chylous substance from the mucosal surface ( $\bullet$ Fig. 1 b).

These became obscure as the capsule advanced, with diminutive whitish spots or mosaic mucosal patterns as the only findings in the middle and the distal part of the small bowel. Oral double-balloon endoscopy (DBE) also identified numerous filiform-like polyps as well as diminutive whitish spots in the distal duodenum and in the jejunum ( $\bullet$ Fig. 2).

Histologic examination of the biopsy specimens taken from the whitish mucosa showed obviously dilated lymphatics in the lamina propria mucosa ( $\mathbf{F i g . 3}$ ), compatible with the diagnosis of intestinal lymphangiectasia.

In intestinal lymphangiectasia, dilated lymphatic vessels in the intestinal wall are usually seen as diminutive whitish spots or whitish reticular mucosal pattern
[1]. However, unusual endoscopic findings, similar to our case, have been recently reported in patients with markedly dilated lymphatic vessels in the submucosa [2]. It thus seems possible that the observed multiple polyposis-like pattern is an endoscopic feature of an advanced stage of intestinal lymphangiectasia.

Small intestinal polyps are found in various intestinal pathologies, such as familial adenomatous polyposis [3], CronkhiteCanada syndrome [4], and multiple lymphomatous polyposis [5]. Our endoscopic findings suggest that intestinal lymphangiectasia should be considered among the differential diagnoses in patients with small intestinal polyps found by capsule endoscopy or DBE. On such occasions, alterations in the surrounding mucosa characterized by whitish villi and chylous exudates could be indicative of intestinal lymphangiectasia.

\section{Competing interests: None}

Endoscopy_UCTN_Code_CCL_1AC_2AC Endoscopy_UCTN_Code_CCL_1AC_2AH 


\section{A. Hirano ${ }^{1}$, T. Matsumoto ${ }^{1}$, M. Esaki ${ }^{1}$,} K. Fujita' ${ }^{2}$, M. lida ${ }^{1}$

1 Department of Medicine and Clinical Science, Graduate School of Medical Sciences, Kyushu University, Fukuoka, Japan

2 Department of Anatomic Pathology, Graduate School of Medical Sciences, Kyushu University, Fukuoka, Japan

\section{References}

1 Asakura H, Miura S, Morishita T et al. Endoscopic and histopathological study on primary and secondary intestinal lymphangiectasia. Dig Dis Sci 1981; 26: $312-320$

2 Safatle-Ribeiro AV, Iriya K, Couto DS et al. Secondary lymphangiectasia of the small bowel: utility of double balloon enteroscopy for diagnosis and management. Dig Dis 2008; 26: $383-386$

3 Matsumoto T, Esaki M, Yanaru-Fujisawa R et al. Small-intestinal involvement in familial adenomatous polyposis: evaluation by double-balloon endoscopy and intraoperative enteroscopy. Gastrointest Endosc 2008; 65: 911-919

4 Cao XC, Wang BM, Han ZC. Wireless capsule endoscopy finding in Cronkhite-Canada syndrome. Gut 2006; 55: 899-900

5 Nakamura S, Matsumoto T, Umeno J et al. Endoscopic features of intestinal follicular lymphoma: the value of double-balloon enteroscopy. Endoscopy 2007; 39: E26-E27

Bibliography

DOI $10.1055 / \mathrm{s}-0029-1244225$

Endoscopy 2010; 42: E281-E282

(c) Georg Thieme Verlag KG Stuttgart · New York . ISSN 0013-726X
Corresponding author

\section{A. Hirano, MD}

Department of Medicine and Clinical Science Graduate School of Medical Sciences Kyushu University

Maidashi 3-1-1

Higashi-ku

Fukuoka 812-8582

Japan

Fax: +81-92-6425273

atsuhira@intmed2.med.kyushu-u.ac.jp 